\title{
The Basis for Thinopyrum-Derived Resistance to Cereal yellow dwarf virus
}

\author{
Hathaithip Wiangjun and Joseph M. Anderson
}

\begin{abstract}
First author: Plant Biology Program, Department of Agronomy, Purdue University, West Lafayette, IN 47907; and second author: Crop Production and Pest Control Research, U.S. Department of Agriculture-Agricultural Research Service, Department of Agronomy, Purdue University, West Lafayette, IN 47907.
\end{abstract}

Accepted for publication 14 June 2004.

\begin{abstract}
Wiangjun, H., and Anderson, J. M. 2004. The basis for Thinopyrumderived resistance to Cereal yellow dwarf virus. Phytopathology 94:11021106.

Incorporation of Thinopyrum intermedium-derived resistance genes into improved wheat germ plasm generated a wheat substitution line (P29) which is completely resistant to Cereal yellow dwarf virus (CYDV). The undetectable CYDV titer in P29 led many to conclude that resistance prevented viral replication. To determine whether CYDV replication or movement is inhibited, we examined inoculated leaves for replication and uninoculated leaves for systemic spread. CYDV subgenomic RNA, pro-

duced only during replication, was found within the inoculated area of P29 and T. intermedium leaves, demonstrating that viral replication occurred. Absence of CYDV from uninoculated, newly emerging leaves of inoculated P29 and T. intermedium plants indicated resistance via inhibition of viral systemic infection. Resistance was not effective if P29 was inoculated with 50 to 100 viruliferous aphids per plant at the first-leaf stage or younger, resulting in a systemic spread of CYDV. As these infected P29 seedlings continued to grow, the resistance phenotype was recovered. Our data suggested that $T$. intermedium-derived resistance to CYDV was primarily dosage dependent and could be developmentally regulated if the amount of inoculum was large enough.
\end{abstract}

Cereal yellow dwarf virus (CYDV) is a single-stranded plussense RNA virus, a member of the genus Polerovirus within the family Luteoviridae (13). CYDV is phloem limited and requires aphid vectors for transmission. Absence of natural resistance in wheat to CYDV led to the search for resistance in wild relatives. The identification of resistance in several Thinopyrum spp. was based upon negative transmission test results and undetectable viral titer as measured by enzyme-linked immunosorbent assay (ELISA) (20,23). Although the distinction between the resistant host and nonhost characteristics of the wheatgrass parents were not addressed, the progeny from these wide crosses proved that their wheatgrass parents carried resistance genes. Wheat substitution line P29, whose 7D chromosome was replaced with Thinopyrum intermedium chromosome $7 \mathrm{E}$, was completely resistant to CYDV $(4,19,22)$.

The mechanism of $T$. intermedium-derived resistance to CYDV was speculated to prevent replication because virus was not detected by ELISA $(8,21,23)$. Replication of CYDV within mesophyll protoplasts isolated from CYDV-resistant P29 seedlings provided an alternative possibility that resistance may interfere with viral movement (2). Because CYDV is phloem limited, replication in mesophyll cells did not preclude the inhibition of replication within vascular tissue, specifically companion cells, sieve elements, and phloem parenchyma (10). In addition, resistance expressed within intact plants may or may not be functional in protoplasts. Protoplasts isolated from potato cv. Maris Piper, a local-lesion host carrying the Nx gene, did not show a hypersensitive response (HR) to Potato virus $X$ infection (1). Similarly, the

Corresponding author: J. M. Anderson; E-mail address: jmanders@ @urdue.edu

Publication no. P-2004-0804-02R

This article is in the public domain and not copyrightable. It may be freely reprinted with customary crediting of the source. The American Phytopathological Society, 2004
Tm-2 and Tm- $2^{2}$ genes conferring HR in resistant tomato plants did not function within protoplasts (16).

Whether CYDV replicates in phloem cells of resistant hosts remains unknown. The purpose of this study was to test the hypothesis that $T$. intermedium-derived resistance allows CYDV to replicate within initially infected cells but inhibits viral movement.

\section{MATERIALS AND METHODS}

Plant material. Two lines of wheat (Triticum aestivum L.) and one wheatgrass (Thinopyrum intermedium) cv. Oahe accession 142012, (Curtis and Curtis, Inc., Clovis, NM) were used for analysis: the CYDV-susceptible cv. Abe (17); the CYDV-resistant substitution line P29 (22); and Oahe, a CYDV-resistant hexaploid forage wheatgrass that was the donor of the $7 \mathrm{E}$ wheatgrass chromosome to P29 (4,20). Seed of each line were planted in 4-in. pots and grown in a growth chamber at $18^{\circ} \mathrm{C}$ with a 16 -h light, 8-h dark cycle and 50\% humidity. Viruliferous aphids (Rhopalosiphum padi L.) were used to transmit CYDV strain NY-RPV. Viruliferous aphids were maintained on CYDV-susceptible oat (Avena sativa L., cv. Clintland 64) in a growth chamber at $18^{\circ} \mathrm{C}$ with a 16-h light, 8-h dark cycle.

Replication and systemic spread analysis. Two experiments were done to determine if CYDV could replicate and spread in resistant wheat and wheatgrass lines. In these experiments, plants were inoculated at the two-leaf stage with 40 to 50 viruliferous aphids per plant. Aphids were caged onto both leaves inside a 4to 5-in. clear straw plugged at both ends with a small piece of cotton. The straws were removed the following day and the inoculated area was marked. After removal of the straws, most aphids remained stationary. Plants were infested for a total of 3 days and then the aphids were killed with malathion. Uninfested control plants were placed in a different growth chamber with identical environmental conditions during the infestation period. All treated and control plants were sprayed with malathion at the same time. 
There were 20 inoculated plants of each test host: Abe, P29, and $T$. intermedium. Two additional replicates were performed at the same time. The negative controls included 20 uninfested plants of each test host. The inoculated area of the leaves was collected from three to four randomly chosen plants at 3 to $4 \mathrm{~h}$ postinfestation (hpi), and 3, 6, and 12 days postinoculation (dpi). Random numbers generated by the SAS statistical software (SAS Institute, Cary, NC) were employed in collecting samples.

Northern blot analysis for the subgenomic RNA of CYDV. Total RNA was isolated with Trizol (Invitrogen Corp., Carlsbad, CA) according to the manufacturer's suggested protocol. Concentration and quality of the RNA were assayed by light absorption at wavelength of 260 and $280 \mathrm{~nm}$ with a Hewlett Packard 8452A DIODE Array spectrophotometer. Total RNA collected from each time point $(20 \mu \mathrm{g})$ was loaded onto a $1 \%$ agarose and $6.66 \%$ formaldehyde gel and subjected to electrophoresis for 5 to $6 \mathrm{~h}$ in $1 \times$ MOPS buffer (18). The gel was treated with $50 \mathrm{mM} \mathrm{NaOH}$ for $30 \mathrm{~min}$, three changes of deionized water for $10 \mathrm{~min}$ each, and $20 \times \mathrm{SSC}(1 \times \mathrm{SSC}$ is $0.15 \mathrm{M} \mathrm{NaCl}$ plus $0.015 \mathrm{M}$ sodium citrate) for $30 \mathrm{~min}$. The RNA was transferred onto a noncharged nylon membrane (Osmonics, Minnetonka, MN) in 20x SSC overnight. The RNA was covalently linked to the membrane by UV irradiation with a UV Stratalinker 2400 (Stratagene, La Jolla, CA) followed by baking at $80^{\circ} \mathrm{C}$ under vacuum for $3 \mathrm{~h}$. Membranes were prehybridized with a solution containing $0.25 \mathrm{M} \mathrm{Na}_{2} \mathrm{HPO}_{4}$ (pH 7.2), 1 mM EDTA (pH 8.0), 20\% SDS, and 0.5\% Boehringer Blocking reagent at $68^{\circ} \mathrm{C}$ for $6 \mathrm{~h}$ (7). The digoxigenin (DIG)labeled probe was then added, and hybridization took place overnight at $68^{\circ} \mathrm{C}$. Membranes were washed three times at $65^{\circ} \mathrm{C}$ for 20 min each with washing buffer containing $20 \mathrm{mM} \mathrm{Na}_{2} \mathrm{HPO}_{4}$ (pH 7.2), 1 mM EDTA ( $\mathrm{pH} 8.0$ ), and $1 \%$ sodium dodecyl sulfate (SDS) (7). Detection was done at room temperature as follows: $5 \mathrm{~min}$ in buffer $1(0.01 \mathrm{M}$ Tris- $\mathrm{HCl}, \mathrm{pH} 7.5$, and $0.15 \mathrm{M} \mathrm{NaCl})$, $30 \mathrm{~min}$ in buffer $2(0.01 \mathrm{M}$ Tris- $\mathrm{HCl}, \mathrm{pH} 7.5,0.15 \mathrm{M} \mathrm{NaCl}$, and $5 \%$ Carnation nonfat dry milk), $30 \mathrm{~min}$ in buffer 2 containing 1:15,000 Anti-DIG antibody (Roche, Indianapolis, IN), $10 \mathrm{~min}$ in buffer 2 for three changes, $10 \mathrm{~min}$ in buffer 1 for three changes, 5 min in buffer $3(0.1 \mathrm{M}$ Tris- $\mathrm{HCl}, \mathrm{pH} 9.5$, and $0.1 \mathrm{M} \mathrm{NaCl})$, and finally $20 \mathrm{~min}$ in buffer 3 containing $2 \mu \mathrm{l}$ of disodium phenyl phosphate (CSPD) (Roche) per $1 \mathrm{ml}$ of buffer 3. The membrane then was exposed to Kodak BioMax film (Kodak, Rochester, NY).

Probe labeling. Probe complementary to the CYDV aphid transmission domain of the coat protein (nucleotide positions 4715 to 5011 of CYDV genomic RNA, accession no. NC_004751) was labeled with digoxigenin by an in vitro transcription reaction consisting of $2 \mu \mathrm{g}$ of template linearized by BamH1 digestion at nucleotide position $4711,2 \mu \mathrm{l}$ of $10 \times$ DIG-RNA labeling mix (Roche), $2 \mu \mathrm{l}$ of T7 MegaScript enzyme mix (Ambion, Austin, TX), $2 \mu$ of $10 \times$ transcription buffer (Ambion), and Nucleasefree water (Ambion) to $20 \mu \mathrm{l}$. The template contained the CYDV genomic RNA (gRNA) region corresponding to nucleotide positions 3975 to 5011 cloned into pGEM-T Easy Vector (Promega Corp., Madison, WI). The labeling reaction was carried out at $37^{\circ} \mathrm{C}$ for $4 \mathrm{~h}$. The DNA template subsequently was degraded with 2 units of DNAse I. The probe was precipitated with $25 \mu \mathrm{l}$ of $7.5 \mathrm{M} \mathrm{LiCl}, 50 \mathrm{mM}$ EDTA at $-80^{\circ} \mathrm{C}$ for $2 \mathrm{~h}$ and then washed with $70 \%$ ethanol.

Reverse-transcription polymerase chain reaction. Total RNA was used in the reverse transcriptase (RT) reaction (Invitrogen) assembled according to the manufacturer's suggested protocol. Random hexamers were used to synthesize first-strand cDNA of which $1 \mu \mathrm{l}$ was included in the $25-\mu \mathrm{l}$ polymerase chain reaction (PCR) composed of $2.5 \mu \mathrm{l}$ of $10 \times \mathrm{Mg}$-free PCR buffer (Promega Corp.), $1.5 \mu \mathrm{l}$ of $25 \mathrm{mM} \mathrm{MgCl}_{2}, 0.5 \mu \mathrm{l}$ of $20 \mathrm{mM} \mathrm{dNTP,} 0.5 \mu \mathrm{l}$ of $10 \mu \mathrm{M}$ CYDV forward primer (5'-ACGTCACAGCCCATAAAACC-3', accession no. NC_004751, open reading frames [ORFs] 1 and 2), $0.5 \mu \mathrm{l}$ of $10 \mu \mathrm{M}$ CYDV reverse primer (5'-CGCATATCCAATGTGCTCCT-3'), $1 \mu$ of Taq polymerase, and deionized water to $25 \mu \mathrm{l}$. The reaction was carried out as follows: 1 cycle at $95^{\circ} \mathrm{C}$ for $5 \mathrm{~min} ; 40$ cycles of $95^{\circ} \mathrm{C}$ for $30 \mathrm{~s}, 55^{\circ} \mathrm{C}$ for $30 \mathrm{~s}$, and $72^{\circ} \mathrm{C}$ for $2 \mathrm{~min}$; and 1 cycle at $72^{\circ} \mathrm{C}$ for $10 \mathrm{~min}$. Amplification of GAPDH under the identical conditions as above with the forward primer (5'-GGTGCCAAGAAGGTCATCAT-3') and the reverse primer (5'-CAAAGTGGTCGTTCAGAGCA-3') was a positive control for first-strand cDNA synthesis.

Tests for resistance at different stages of plant development. Abe and P29 were planted 4 to 5 days apart to obtain two-leaf, one-leaf, and expanding-leaf stage (first leaf not fully expanded) plants. For heavily inoculated plants, whole plants were infested with 50 to 100 viruliferous aphids. For lightly inoculated plants, 7 to 10 aphids were caged onto a 1-in. area of the leaves. The plants were infested for 2 days prior to an application of malathion. There were three replicates of the inoculated samples and one replicate of the uninfested control plants (15 plants per replicate). The inoculated area of the leaves was harvested at 10 dpi from four to seven plants and then pooled. At $16 \mathrm{dpi}$, the uninoculated, newly emerging second leaves (6 to 8 in. in length) were collected, pooled, and tested for systemic spread of CYDV by RT-

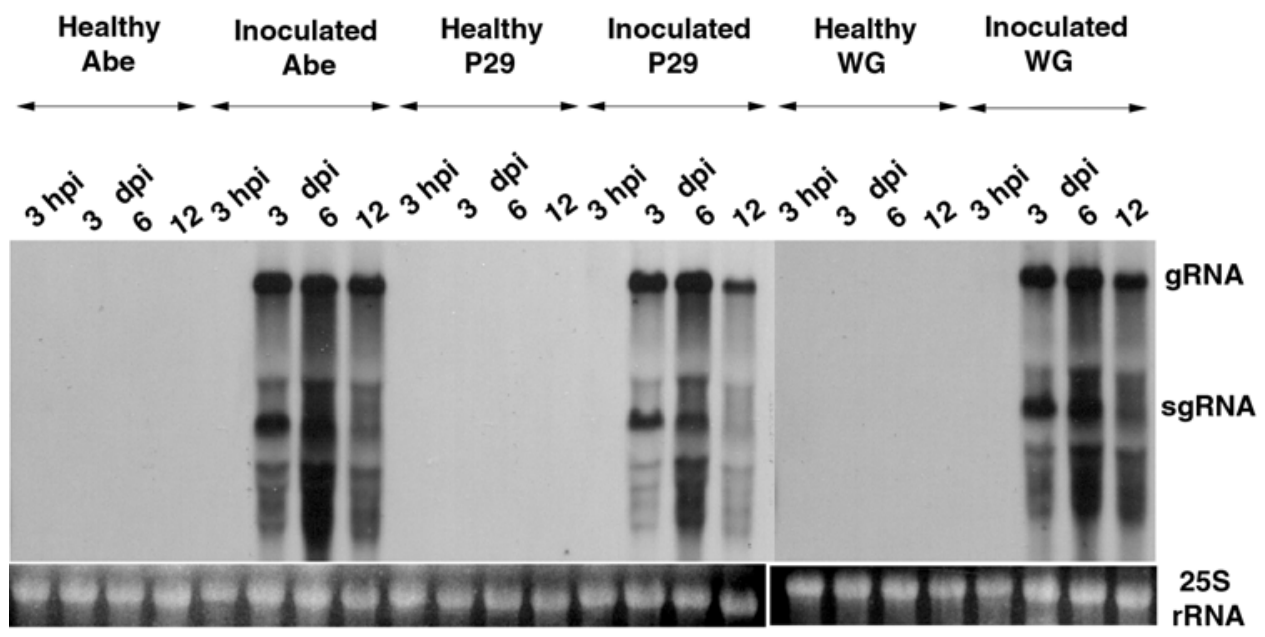

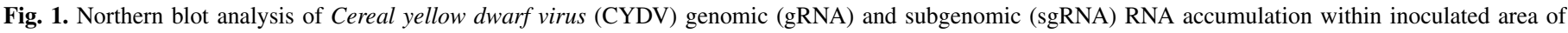

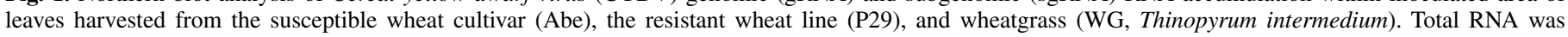

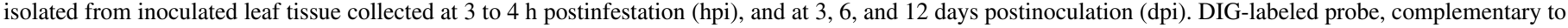

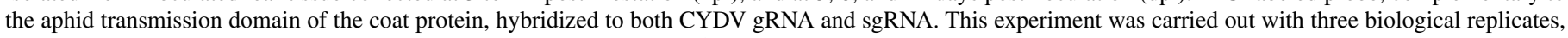
all of which yielded similar results. Data of one replicate is presented. $25 \mathrm{~S}$ rRNA stained with ethidium bromide is shown as a control for gel loading. 
PCR. To check for a recovery phenotype, these plants were allowed to grow and the uninoculated, newly emerging fourth leaves were assayed by RT-PCR for the presence of CYDV at 25 dpi.

ELISA. Tissue of uninoculated, newly emerging second leaves exhibiting systemic spread of CYDV was ground in liquid nitrogen, after which phosphate-buffered saline solution $(140 \mathrm{mM}$ $\mathrm{NaCl}, 2.7 \mathrm{mM} \mathrm{KCl}, 8.1 \mathrm{mM} \mathrm{Na}_{2} \mathrm{HPO}_{4}$, and $1.5 \mathrm{mM} \mathrm{KH}_{2} \mathrm{PO}_{4}, \mathrm{pH}$ 7.4) was added at a $1: 10$ ratio ( $\mathrm{wt} / \mathrm{vol}$ ). Viral titer was assayed by double-antibody sandwich (DAS)-ELISA according to Anderson et al. (2).

\section{RESULTS}

CYDV replication in $\mathbf{P 2 9}$ and $\boldsymbol{T}$. intermedium. CYDV subgenomic RNA (sgRNA) produced by the viral RNA-dependent RNA polymerase during replication was used as an indicator of CYDV replication in the resistant hosts P29 and T. intermedium. The experiments were conducted twice, with similar results obtained. Data from the second experiment are presented in Figure 1. Northern blot analysis of inoculated leaves of P29, susceptible parent Abe, and resistant parent T. intermedium showed comparable amounts of sgRNA, indicating efficient replication of CYDV. No virus was detected at time zero ( 3 to $4 \mathrm{hpi}$ ) or within the uninfested controls. The smear present in RNA isolated from infected samples may be degraded viral RNA due to senescence. The bright banding pattern above and below the sgRNA corresponded to the location of ribosomal RNAs which probably prevented transfer or hybridization.

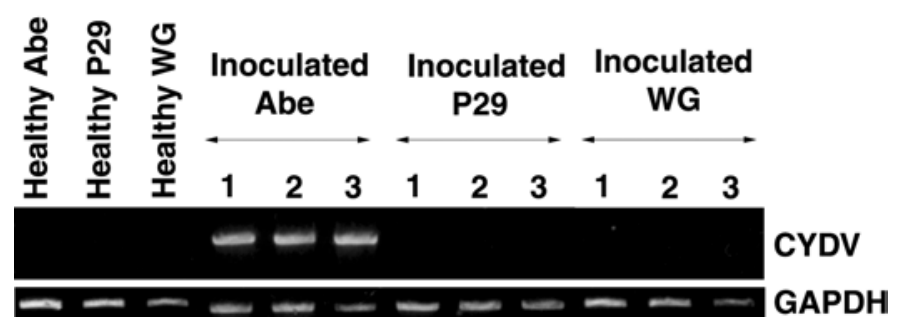

Fig. 2. Reverse-transcriptase polymerase chain reaction (RT-PCR) assay of Cereal yellow dwarf virus (CYDV) within uninoculated, newly emerging second leaves of susceptible wheat cultivar (Abe), resistant wheat line (P29), and wheatgrass (WG, Thinopyrum intermedium) plants previously analyzed in Figure 1. PCR of GAPDH was used as a positive control for first-strand cDNA synthesis reactions. The numbers 1, 2, and 3 represent three biological replicates.
Systemic spread of CYDV. Uninoculated, newly emerging second leaves of plants used in Northern blot analyses were assayed for systemic viral spread by amplification of CYDV ORFs 1 and 2 via RT-PCR. The virus spread readily in Abe, whereas no systemic infection was detected in P29 and T. intermedium (Fig. 2). Amplification of GAPDH as a positive control for RT reactions demonstrated that the absence of virus in some samples was not due to failure of cDNA synthesis.

Age-related resistance in P29. Based on the above data, resistance in P29 interfered with systemic spread of CYDV. The inability of CYDV to systemically accumulate in P29 was used to identify conditions in which resistance could be overcome or was not effective. Inoculum dosage and stage of development of plants at the time of inoculation were tested. The presence of CYDV within inoculated leaves assayed at 10 dpi confirmed successful inoculation. At $16 \mathrm{dpi}$, the virus had moved systemically in Abe to the uninoculated, newly emerging second leaves regardless of the stage of development at the time of inoculation or how many aphids were used (Fig. 3). In contrast, only high inoculum pressure resulted in detection of a low amount of CYDV in uninoculated, newly emerging second leaves of P29 plants inoculated at the one-leaf (detected only in one of three biological replicates) and expanding-leaf stages (Fig. 3). Tissue obtained from uninoculated, newly emerging second leaves of the samples exhibiting CYDV systemic infection (Fig. 3) was assayed for viral titer by DAS-ELISA (Table 1). Although RTPCR amplification of CYDV within the newly emerging leaves was positive for both Abe and P29 inoculated at the one-leaf and expanding-leaf stages (Fig. 3), only Abe yielded a measurable viral titer. As inoculated P29 plants continued to develop, the resistance phenotype was recovered, as shown by the lack of CYDV amplification within uninoculated, newly emerging fourth

TABLE 1. Cereal yellow dwarf virus titer in the uninoculated, newly emerging second leaves of susceptible (Abe) and resistant (P29) plants exhibiting a systemic infection

\begin{tabular}{lcc}
\hline Plant stage inoculated & Cultivar & ELISA value $^{\mathrm{a}}$ \\
\hline Healthy control & Abe & -0.006 \\
One-leaf & P29 & -0.003 \\
& Abe & 0.51 \\
Expanding-leaf & P29 & 0.045 \\
& Abe & 0.425 \\
& P29 & -0.005 \\
\hline
\end{tabular}

a Enzyme-linked immunosorbent assay; average of three biological replicates, each of which was measured in triplicate $2 \mathrm{~h}$ after adding substrate.

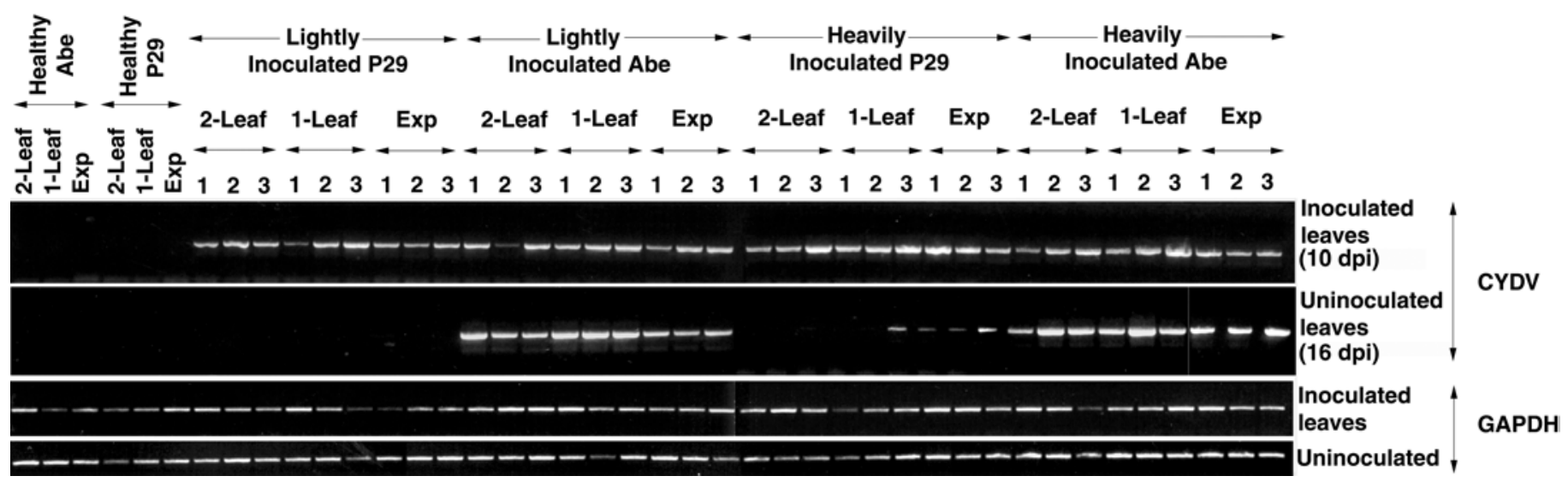

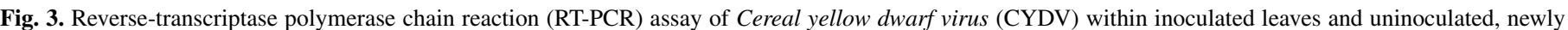

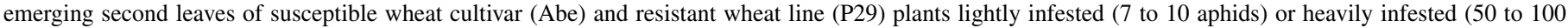

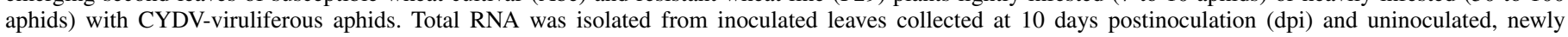

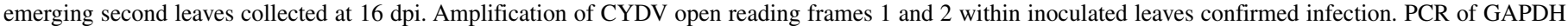

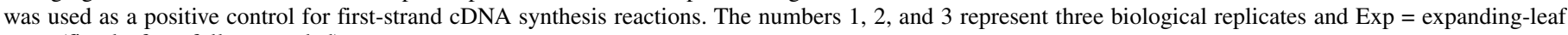
stage (first leaf not fully expanded). 
leaves, which indicated an inhibition of further systemic infection (Fig. 4).

\section{DISCUSSION}

Due to the aphid-borne nature of CYDV, the mechanism of T. intermedium-derived resistance may act at the level of aphid feeding or processes associated with viral infection. Shukle et al. (23) eliminated the first possibility by electronically monitoring aphid feeding and found that vector behavior was not altered on T. intermedium. In addition, our preliminary data (unpublished data) revealed the presence of CYDV within the inoculated area of infected P29 leaves. Consequently, viral replication was assessed for this area of inoculated plants. By caging aphids during the inoculation access period, the site of infection could be localized, thereby minimizing the dilution factor of viral RNA relative to total RNA isolated. This strategy enabled CYDV sgRNA detection by Northern blot analyses.

The sgRNA was used as an indicator of CYDV replication because it is produced only during replication from minus-strand RNA and because CYDV does not propagate in aphid vectors $(14,25)$. In addition, sgRNA was not observed in Northern blot analysis of RNA isolated from the purified virions of Potato leafroll virus, another member of the genus Polerovirus (15). The presence of sgRNA within inoculated leaves supports the hypothesis that $T$. intermedium-derived CYDV resistance does not interfere with viral replication within infected cells. The abundance of sgRNA in Abe, P29, and T. intermedium indicated that CYDV replicated efficiently in both susceptible and resistant hosts. This also was the case for bell pepper plants expressing a mature resistant phenotype, where there was no significant difference in the accumulation of Cucumber mosaic virus (CMV) within the inoculated leaves of small and large plants (9).

When resistance was maintained, the lack of amplification of CYDV from uninoculated, newly emerging leaves of P29 and T. intermedium indicated a lack of systemic infection. However, this may not represent a lack of systemic movement. Derrick and Nelson (5) suggested that long-distance transport and subsequent viral accumulation were independent events. This model was supported by distribution of the Cucurbita spp. phloem-specific PP1 protein produced only in the genus Cucurbita. Intergeneric grafts between Cucurbita rootstocks and Cucumis scions showed that the PP1 protein, which was transported from Cucurbita rootstocks, localized mainly to the sieve elements of Cucumis scions but not to companion cells (11). If long-distance transport of

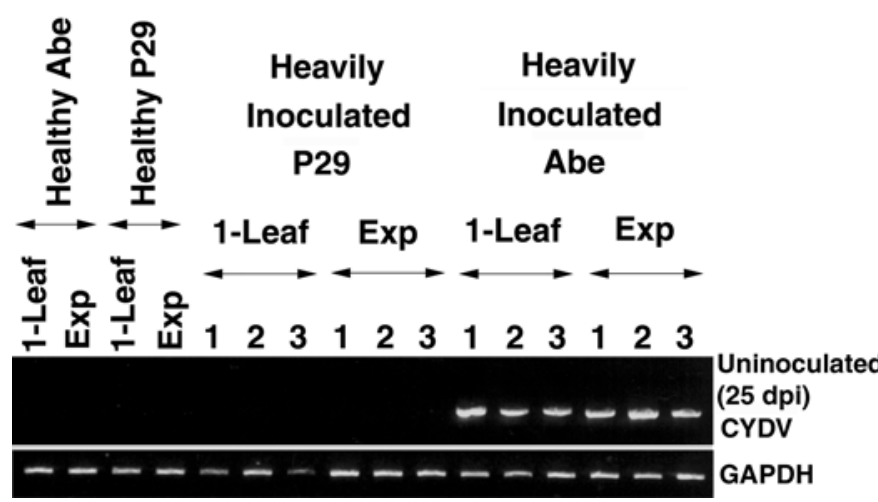

Fig. 4. Reverse-transcriptase polymerase chain reaction (RT-PCR) assay of Cereal yellow dwarf virus (CYDV) within uninoculated, newly emerging fourth leaves of susceptible wheat cultivar (Abe) and resistant wheat line (P29) plants heavily infested at first-leaf and expanding-leaf stages previously examined in Figure 3. Tissue was collected 25 days postinoculation (dpi). PCR of GAPDH was used as a positive control for first-strand cDNA synthesis reactions. The numbers 1, 2, and 3 represent three biological replicates an Exp = expanding-leaf stage.
CYDV in P29 is similar to that of PP1 protein, where CYDV could exit the initial site of infection but could not re-enter companion cells at distal locations, the amount of CYDV within sieve elements alone might not be sufficient to be detected by RT-PCR. Unfortunately, we cannot perform a similar experiment because grafting cannot be carried out in monocots.

Resistance to plant viruses, in several cases, has been recognized as a developmentally regulated process $(6,12,24)$. Bell pepper (Capsicum annuum 'Early Calwonder') plants were systemically infected by CMV only if inoculated plants were of small and medium sizes, but not when they were larger (9). Under high inoculum pressure, resistance in P29 was not observed if plants were inoculated at the one-leaf stage or younger (Fig. 3). The recovery phenotype (Fig. 4) subsequently shown by infected P29 plants as they matured further supported the observation that expression of resistance was gradual. Additional data obtained from lightly inoculated P29 plants, where resistance was maintained across all developmental stages tested, suggested that $T$. intermedium-derived resistance was primarily dosage dependent and could be developmentally regulated if the inoculum pressure was sufficiently high.

Although large numbers of aphids used for inoculation may have predisposed plants to be more susceptible to CYDV infection, the development of infected Abe, infected P29, and uninfested controls were similar (data not shown). Burnett and Gill (3) also showed no yield loss on wheat, oat, and barley infested with 100 nonviruliferous aphids for 2 days. Therefore, systemic spread of CYDV was most likely the result of high inoculum pressure. Nevertheless, additive effects between aphid feeding and viral infection, if they exist, could not be ruled out.

The lack of CYDV amplification from uninoculated, newly emerging leaves of P29 may be due to an absence of the virus as a result of inhibition of systemic movement or due to an insufficient detection limit of the assay. Based on the data obtained, we propose the following models for $T$. intermedium-derived resistance to CYDV. In the phloem-restriction model, CYDV is restricted to the initially infected companion cells where it replicates (Fig. 5A). The inhibition of long-distance transport model states that CYDV can spread from these companion cells into adjacent sieve elements but movement beyond this point is

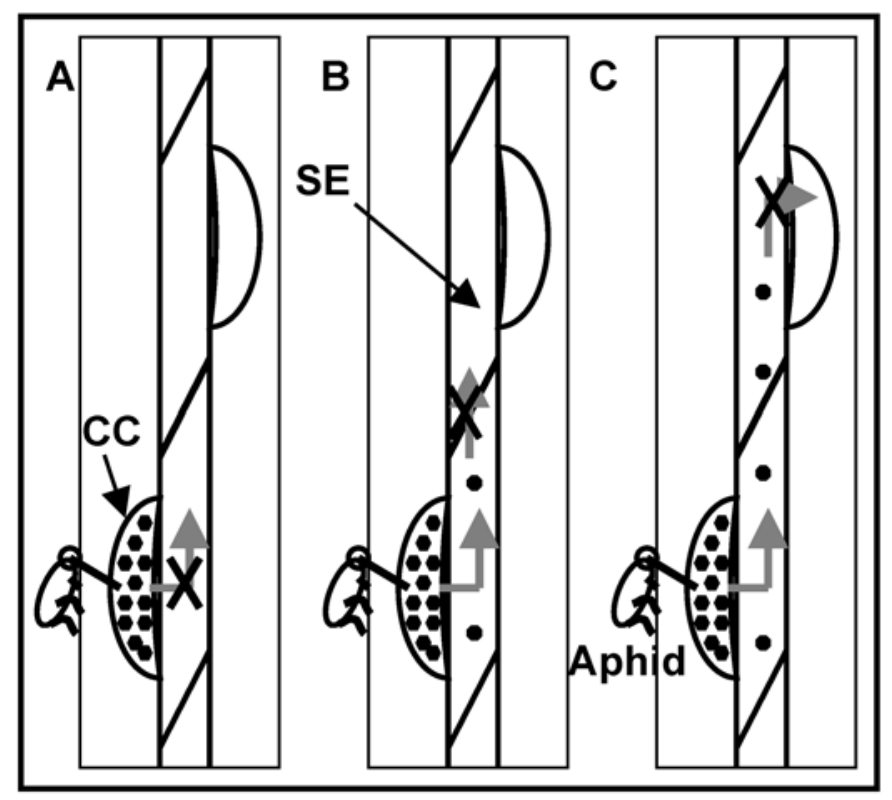

Fig. 5. Cereal yellow dwarf virus resistance mechanism models. This diagram represents longitudinal sections of inoculated leaves of P29 plants. A, Phloem-restriction model, B, inhibition of long-distance transport model, and $\mathbf{C}$, inhibition of re-entry model. $\mathrm{CC}=$ companion cell, $\mathrm{SE}=$ sieve element, and dark hexagons are virus particles or virus RNA. 
blocked (Fig. 5B). The inhibition of re-entry model proposes that CYDV can move systemically through sieve elements but cannot re-enter companion cells at distal locations for replication (Fig. 5C). To test the above models, cellular localization of CYDV within P29 tissue must be assessed.

\section{ACKNOWLEDGMENTS}

Mention of a trademark, proprietary product, trade names, or commercial products in this article is solely for the purpose of providing scientific information; it does not constitute a guarantee, warranty, recommendation, or endorsement by the USDA and does not imply approval to the exclusion of other products that also may be suitable. Financial support was provided by USDA-ARS CRIS project 3602-21220-008-00D and SCA project 58-3602-2-152. We thank S. Goodwin, S. Loesch-Fries, R. Nicholson, and H. Ohm for comments on the article; and L. Ayala and N. Thompson for technical advice. Published as paper 6540 Purdue University Agricultural Research Program.

\section{LITERATURE CITED}

1. Adams, S. E., Jones, R. A. C., and Coutts, R. H. A. 1985. Infection of protoplasts derived from potato shoot cultures with Potato virus X. J. Gen. Virol. 66:1341-1346.

2. Anderson, J. M., Bucholtz, D. L., Greene, A. E., Francki, M. G., Gray, S. M., Sharma, H., Ohm, H. W., and Perry, K. L. 1998. Characterization of wheatgrass-derived Barley yellow dwarf virus resistance in a wheat alien chromosome substitution line. Phytopathology 88:851-855.

3. Burnett, P. A., and Gill, C. C. 1976. The response of cereals to increased dosage with Barley yellow dwarf virus. Phytopathology 66:646-651.

4. Crasta, O. R., Francki, M. G., Bucholtz, D. B., Sharma, H. C., Zhang, J., Wang, R. C., Ohm, H. W., and Anderson, J. M. 2000. Identification and characterization of wheat-wheatgrass translocation lines and localization of Barley yellow dwarf virus resistance. Genome 43:698-706.

5. Derrick, P. M., and Nelson, R. S. 1999. Plasmodesmata and long-distance virus movement. Pages 315-339 in: Plasmodesmata: Structure, Function, Role in Cell Communications. A. J. E. van Bel and W. J. P. van Kesteren, eds. Springer-Verlag, Berlin.

6. DiFonzo, C. D., Ragsdale, D. W., and Radcliffe, E. B. 1994. Susceptibility to Potato leafroll virus in potato: Effects of cultivar, plant age at inoculation, and inoculation pressure on tuber infection. Plant Dis. 78:1173-1177.

7. Engler-Blum, G., Meier, M., Frank, J., and Müller, G. A. 1993. Reduction of background problems in nonradioactive Northern and Southern blot analyses enables higher sensitivity than ${ }^{32} \mathrm{P}$-based hybridizations. Anal. Biochem. 210:235-244.
8. Francki, M. G., Ohm, H. W., and Anderson, J. M. 2001. Novel germplasm providing resistance to Barley yellow dwarf virus in wheat. Aust. J. Agric. Res. 52:1375-1382.

9. Garcia-Ruiz, H., and Murphy, J. F. 2001. Age-related resistance in bell pepper to Cucumber mosaic virus. Ann. Appl. Biol. 139:307-317.

10. Gill, C. C., and Chong, J. 1975. Development of the infection in oat leaves inoculated with Barley yellow dwarf virus. Virology 66:440-453.

11. Golecki, B., Schulz, A., and Thompson, G. A. 1999. Translocation of structural P proteins in the phloem. Plant Cell 11:127-140.

12. Kus, J. V., Zaton, K., Sarkar, R., and Cameron, R. K. 2002. Age-related resistance in Arabidopsis is a developmentally regulated defense response to Pseudomonas syringae. Plant Cell 14:479-490.

13. Mayo, M. A., and D'Arcy, C. J. 1999. Family Luteoviridae: A reclassification of Luteoviruses. Pages 15-22 in: The Luteooviridae. H. G. Smith and $\mathrm{H}$. Barker, eds. CAB International, Wallingford, UK.

14. Mayo, M. A., and Miller, W. A. 1999. The structure and expression of Luteovirus genomes. Pages 23-42 in: The Luteooviridae. H. G. Smith and H. Barker, eds. CAB International, Wallingford, UK.

15. Miller, J. S., and Mayo, M. A. 1991. The location of the $5^{\prime}$ end of the Potato leafroll luteovirus subgenomic coat protein mRNA. J. Gen. Virol. 72:2633-2638

16. Motoyoshi, F., and Oshima, N. 1977. Expression of genetically controlled resistance to Tobacco mosaic virus infection in isolated tomato leaf mesophyll protoplasts. J. Gen. Virol. 34:499-506.

17. Patterson, F. L., Gallum, R. L., Roberts, J. J., Finney, R. E., and Shaner, G. E. 1975. Registration of Authur-71 and Abe wheat. Crop Sci. 15:736.

18. Sambrook, J., and Russell, D. W. 2001. Chapter 7: Extraction, purification, and analysis of mRNA from eukaryotic cells. Pages 7.1-7.94 in: Molecular Cloning. Cold Spring Harbor Laboratory, Cold Spring Harbor, NY.

19. Sharma, H. C., and Gill, B. S. 1983. New hybrids between Agropyron and wheat. Theor. Appl. Genet. 66:111-121.

20. Sharma, H. C., Gill, B. S., and Uyemoto, J. K. 1984. High levels of resistance in Agropyron species to Barley yellow dwarf and Wheat streak mosaic viruses. Phytopathol. Z. 110:143-147.

21. Sharma, H. C., Ohm, H. W., Lister, R. M., Foster, J. E., and Shukle, R. H. 1989. Response of wheatgrasses and wheat $\mathrm{x}$ wheatgrass hybrids to Barley yellow dwarf virus. Theor. Appl. Genet. 77:369-374.

22. Sharma, H. C., Ohm, H. W., and Perry, K. L. 1997. Registration of Barley yellow dwarf virus resistant wheat germplasm line P29. Crop Sci. 37:1032-1033.

23. Shukle, R. H., Lampe, D. J., Lister, R. M., and Foster, J. E. 1987. Aphid feeding behavior: Relationship to Barley yellow dwarf virus resistance in Agropyron species. Phytopathology 77:725-729.

24. Smit, G., and Parlevliet, J. E. 1990. Mature plant resistance of barley to barley leaf rust, another type of resistance. Euphytica 50:159-162.

25. Stewart, G., and Gildow, F. E. 2003 Luteovirus-aphid interactions. Annu. Rev. Phytopathol. 41:539-566. 